\title{
Effects of Perianal Involvement on Clinical Outcomes in Crohn's Disease over 10 Years
}

\author{
Jin Young Yoon ${ }^{1}$, Jae Hee Cheon ${ }^{2}$, Soo Jung Park², Tae II Kim², and Won Ho Kim² \\ ${ }^{1}$ Department of Medicine, Graduate School, Kyung Hee University, and ${ }^{2}$ Department of Internal Medicine and Institute of Gastroenterology, \\ Yonsei University College of Medicine, Seoul, Korea
}

Background/Aims: There was the assumption that Crohn's disease (CD) patients with perianal lesions might have different clinical courses compared to those without. However, quantifiable data comparing the long-term outcomes between the two groups are scarce. Methods: We retrospectively reviewed 221 consecutive patients newly diagnosed with CD and registered at the IBD clinic of Severance Hospital, in Seoul, Korea, between January 1990 and October 2005. We compared patients with perianal $C D$ (PCD) and non-perianal CD (NPCD) in terms of clinical outcomes over 10 years. Results: PCD progressed more frequently from inflammatory to complicated behavior than NPCD. Moreover, corticosteroids were prescribed in 102 patients with PCD and only 57 with NPCD (82.9\% vs 58.2\%, p<0.001), immunosuppressants in 89 and 42 (72.4\% vs 42.9\%, p<0.001), and anti-tumor necrosis factor $\alpha$ (TNF- $\alpha$ ) in 37 and 12 (30.1\% vs $12.2 \%$, $\mathrm{p}=0.002$ ). Cumulative hospitalization rates were $82.1 \%$ in PCD and $72.4 \%$ in NPCD ( $p=0.086)$, and surgical intervention rates were $39.8 \%$ and $51.0 \%$, respectively $(p=0.097$ ). Conclusions: Patients with PCD were more likely than those with NPCD to be administered corticosteroids, immunosuppressants, and anti-TNF- $\alpha$. However, there is no significant difference in the cumulative rates of surgical interventions or hospitalizations. (Gut Liver 2018;12:297-305)

Key Words: Perianal lesion; Crohn disease; Outcomes

\section{INTRODUCTION}

Crohn's disease (CD) is a multifactorial chronic inflammatory bowel disease (IBD) that presents with unpredictable and various clinical courses. The phenotypic heterogeneity of CD makes establishing a practically useful categorization difficult, which has led to diverse classification systems. ${ }^{1}$ In 2000, the Vienna classification system was introduced, and it has been widely used because of its simple framework that divides CD into subgroups according to age at diagnosis, disease location, and disease behavior, including inflammatory (B1), structuring (B2), and penetrating (B3) types. ${ }^{2}$ Earlier studies using the Vienna classification system found that disease behavior changes significantly over time. ${ }^{3,4}$ They also demonstrated that perianal fistulae occur independently of intestinal fistula in the penetrating type. ${ }^{5}$ Thus, in 2005, the Vienna classification was revised to the Montreal classification, ${ }^{6}$ which removed perianal disease from the penetrating type and allowed it to be added to any behavior to indicate simultaneous perianal lesions. However, it has been demonstrated that $\mathrm{CD}$ patients with perianal lesions might have different clinical courses and requirements for surgical or medical treatment than those without perianal lesions. ${ }^{7-9}$ Moreover, specific genetic factors related to perianal $\mathrm{CD}$ (PCD) have been investigated. $^{10-12}$

PCD can involve a variety of perianal lesions during the clinical course, ranging from asymptomatic and mild problems requiring only conservative treatment to severe situations that necessitate urgent surgical interventions, such as complex fistula combined with abscess. ${ }^{13}$ It has also been reported that PCD itself has a more aggressive disease course that requires a more intensive treatment modality than non-perianal CD (NPCD). ${ }^{14,15}$

Unfortunately, quantifiable data comparing the long-term outcomes of PCD and NPCD are scarce, although accurately understanding the distinction in clinical courses between them is critical in determining treatment modalities and accurately predicting clinical outcomes. Most research has dealt with PCD only as a predictive factor of clinical course. ${ }^{7,910,16-19}$ Accordingly, our aim in this study was to identify the measurable differences in long-term (more than 10 years) clinical outcomes

Correspondence to: Won Ho Kim

Department of Internal Medicine and Institute of Gastroenterology, Yonsei University College of Medicine, 50-1 Yonsei-ro, Seodaemun-gu, Seoul 03722, Korea

Tel: +82-2-2228-1950, Fax: +82-2-393-6884, E-mail: kimwonho@yuhs.ac

Received on June 27, 2017. Revised on July 31, 2017. Accepted on August 11, 2017. Published online November 8, 2017 pISSN 1976-2283 eISSN 2005-1212 https://doi.org/10.5009/gnl17275

(e) This is an Open Access article distributed under the terms of the Creative Commons Attribution Non-Commercial License (http://creativecommons.org/licenses/by-nc/4.0) which permits unrestricted non-commercial use, distribution, and reproduction in any medium, provided the original work is properly cited. 
between $\mathrm{CD}$ patients with and without perianal lesions.

\section{MATERIALS AND METHODS}

\section{Study population}

We retrospectively reviewed 236 consecutive patients newly diagnosed with CD and registered at the IBD clinic of Severance Hospital, a tertiary center in Seoul, South Korea, between January 1990 and October 2005. Patients were excluded from our analysis if they were followed up for less than 5 years at our hospital ( $n=13)$, were diagnosed simultaneously with another autoimmune disease $(n=1)$, or visited our clinic while receiving treatment from another hospital $(n=1)$. An established diagnosis of CD was based on a combination of conventional clinical, radiologic, endoscopic, and histopathologic findings. ${ }^{20}$ After confirming the diagnosis of $\mathrm{CD}$, we evaluated the disease status of all patients at an outpatient clinic every 1 to 3 months. At each evaluation, we monitored the patient's clinical symptoms and signs by both interview and questionnaire and also measured their complete blood cell counts and chemistry profiles. Colonoscopies or radiologic imaging studies such as computed tomography were performed at the physician's discretion. In cases of complications such as perforation, bleeding, infection, or severely active disease flare-ups, patients were admitted and treated accordingly. This study was approved by the Institutional Review Board of Severance Hospital (IRB number: 4-20120302).

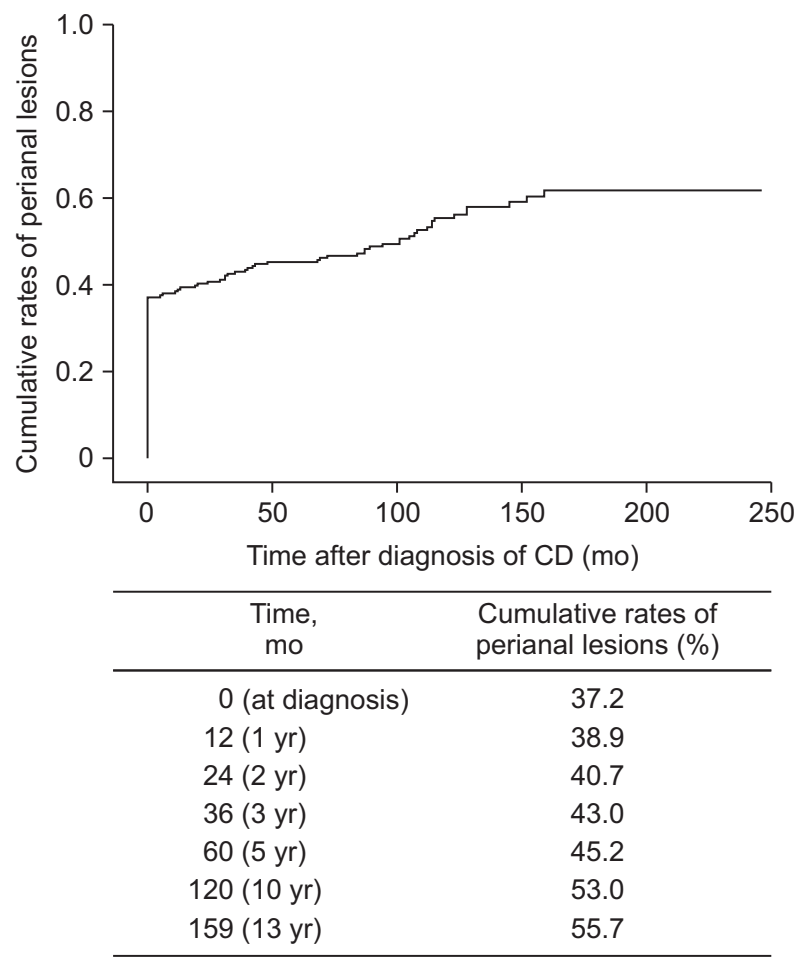

Fig. 1. Cumulative rate of perianal lesions in patients with Crohn's disease.

\section{Methods}

We retrospectively analyzed the baseline demographic data (age at diagnosis, gender, and familial history of IBD) and medical data (disease location and behavior, extraintestinal symptoms, and previous history of appendectomy). In this study, perianal lesions were classified according to the American Gastroenterological Association medical position statement. ${ }^{21}$ In our study, anal fistula, abscess, fissure, and stenosis (except for hemorrhoids and skin tags) were considered perianal lesions related to CD. First, we evaluated the characteristics and cumulative occurrence rate of perianal lesions. To investigate differences in clinical outcomes between PCD and NPCD patients, we evaluated three categories: medical treatments (corticosteroids, immunosuppressants, such as azathioprine or 6-mercaptopurine, and anti-tumor necrosis factor $\alpha$ (TNF- $\alpha$ ) agents, such as infliximab or adalimumab); surgical treatments (except for operations associated with perianal lesions); and hospitalization.

We followed the Montreal classification in determining the location (L1, small bowel; L2, colon; L3, small bowel and colon; and L4, upper gastrointestinal tract) and behavior (B1, inflammatory; B2, stenosis; B3, penetrating). ${ }^{22}$ The general treatment policy for CD in our center is based on a step-up approach. ${ }^{23}$ If $\mathrm{CD}$ patients are unresponsive to prior agents, we use higher step therapies as additions or replacements.

Table 1. Baseline Characteristics $(n=221)$

\begin{tabular}{lccc}
\hline \multicolumn{1}{c}{ Characteristic } & $\begin{array}{c}\text { Patients with } \\
\text { perianal lesions } \\
(\mathrm{n}=123)\end{array}$ & $\begin{array}{c}\text { Patients without } \\
\text { perianal lesions } \\
(\mathrm{n}=98)\end{array}$ & p-value \\
\hline Sex, male/female & $78(63.4) /$ & $55(56.1) /$ & 0.271 \\
& $45(36.6)$ & $43(43.9)$ & \\
Age, yr & $23.4 \pm 7.8$ & $30.3 \pm 13.5$ & $<0.001$ \\
Follow-up period, mo & $120(60-246)$, & $121(61-268)$, & 0.673 \\
& $130.1 \pm 42.2$ & $132.7 \pm 49.7$ & \\
Last status & & & 0.540 \\
Ongoing follow-up & $97(78.9)$ & $71(72.4)$ & \\
Loss of follow-up & $24(19.5)$ & $25(25.5)$ & \\
Death & $2(1.6)$ & $2(2.0)$ & \\
Extraintestinal symptoms & & & 0.083 \\
With & $32(26.0)$ & $16(16.3)$ & \\
Without & $91(74.0)$ & $82(83.7)$ & \\
Family history & & & 0.106 \\
Yes & $12(9.8)$ & $4(4.1)$ & \\
No & $111(90.2)$ & $94(95.9)$ & \\
Previous appendectomy & & & \\
Yes & $16(13.0)$ & $21(21.4)$ & \\
No & $107(87.0)$ & $77(78.6)$ & \\
\hline
\end{tabular}

Data are presented as number (\%), mean \pm SD, or median (range). 

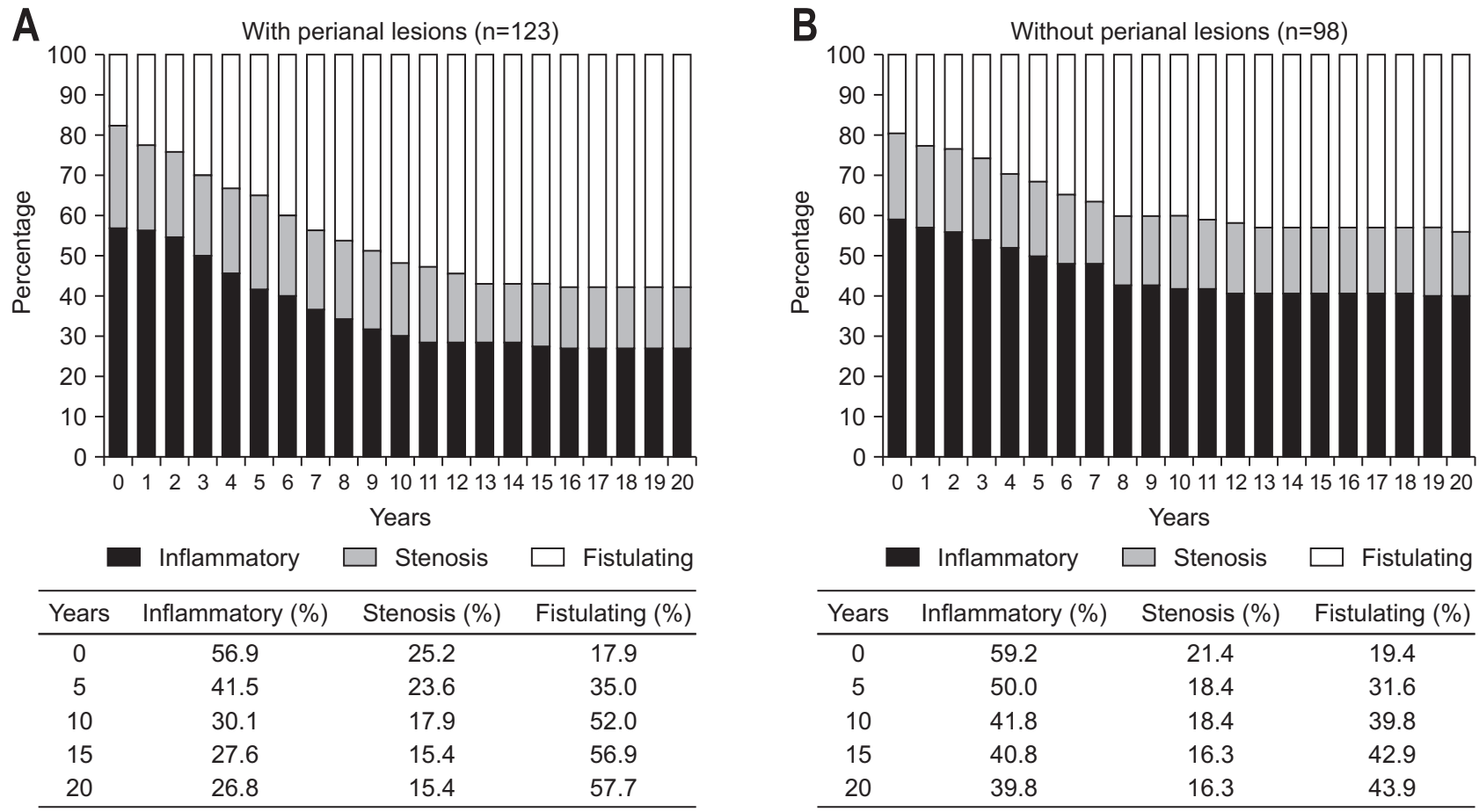

Fig. 2. Tendency of behavior distribution over time between (A) perianal Crohn's disease (CD) and (B) non-perianal CD.

\section{Statistics}

Continuous variables are presented as the mean \pm standard deviation or median (range) and compared using two-sample ttests. Categorical variables were compared by chi-square tests or Fisher exact tests. The Kaplan-Meier method was used to generate the curve, and a log-rank comparison was performed to compare the cumulative probabilities that PCD and NPCD patients would receive specific medical treatments (corticosteroids, immunosuppressants, and anti-TNF- $\alpha$ agents) and surgical treatments. p-values less than 0.05 were considered significant. All statistical analyses were performed using the statistical software package SPSS version 12.0 for Windows (SPSS Inc., Chicago, IL, USA).

\section{RESULTS}

\section{Characteristics and clinical course of disease}

We included $221 \mathrm{CD}$ patients in the study. Of these, 123 patients (55.7\%) eventually developed perianal lesions. PCD was identified in 82 patients (37.1\%) at the time of diagnosis and in 41 patients (18.6\%) thereafter. The perianal lesions included 103 (83.7\%) patients with fistula, 47 (38.2\%) with abscess, 25 (20.3\%) with fissure, and 16 (13.0\%) with stenosis. Eleven cases had only fissure, six cases had only stenosis, and one case had all four types of perianal lesions. The cumulative occurrence rates of perianal lesion were $37.2 \%$ at diagnosis, 38.9\% after 1 year, 43\% after 3 years, $45.2 \%$ after 5 years, and 53.0\% after 10 years (Fig. 1). Of $221 \mathrm{CD}$ patients, 37.2\% (82/221) had perianal
Table 2. Comparison of the Clinical Outcomes with Medication Use

\begin{tabular}{|c|c|c|c|}
\hline Details of outcomes & $\begin{array}{l}\text { Patients with } \\
\text { perianal lesions } \\
\quad(\mathrm{n}=123)\end{array}$ & $\begin{array}{l}\text { Patients without } \\
\text { perianal lesions } \\
\qquad(\mathrm{n}=98)\end{array}$ & p-value \\
\hline Steroid use & 102 (82.9) & $57(58.2)$ & $<0.001$ \\
\hline $\begin{array}{l}\text { No. of flare-up events } \\
\text { requiring steroid } \\
\text { administration }\end{array}$ & $3.3 \pm 2.3$ & $2.4 \pm 1.9$ & 0.015 \\
\hline $\begin{array}{l}\text { Total duration of steroid } \\
\text { administration, day }\end{array}$ & $372.2 \pm 577.2$ & $226.7 \pm 205.8$ & 0.068 \\
\hline $\begin{array}{l}\text { Days of steroid administration } \\
\text { per flare-up }\end{array}$ & $108.4 \pm 114.5$ & $94.6 \pm 45.5$ & 0.383 \\
\hline Immunosuppressants use & $89(72.4)$ & $42(42.9)$ & $<0.001$ \\
\hline $\begin{array}{l}\text { Duration from first steroid } \\
\text { to first immunosuppressant } \\
\text { administration, mo }\end{array}$ & $26.0 \pm 30.7$ & $28.6 \pm 41.8$ & 0.700 \\
\hline Anti-TNF- $\alpha$ therapy use & $37(30.1)$ & $12(12.2)$ & 0.002 \\
\hline $\begin{array}{l}\text { Duration from first } \\
\text { corticosteroid to first } \\
\text { anti-TNF- } \alpha \text { administration, } \\
\text { mo }\end{array}$ & $59.2 \pm 40.1$ & $64.9 \pm 50.5$ & 0.689 \\
\hline $\begin{array}{l}\text { Duration from first } \\
\text { immunosuppressant to } \\
\text { first anti-TNF- } \alpha \\
\text { administration, mo }\end{array}$ & $40.6 \pm 36.8$ & $40.2 \pm 39.5$ & 0.971 \\
\hline
\end{tabular}

Data are presented as number (\%) or mean \pm SD.

TNF- $\alpha$, tumor necrosis factor $\alpha$.

lesion at diagnosis. In other words, among 123 PCD patients, approximately two-thirds of patients (82/123) presented initially perianal lesions. The baseline characteristics of PCD and NPCD 
patients are compared in Table 1 . The mean age at diagnosis was significantly younger in PCD than in NPCD $(23.4 \pm 7.8$ vs $30.3 \pm 13.5, p<0.001)$, but there was no significant difference in gender (male, $63.4 \%$ vs $56.1 \%, p=0.271$ ), mean duration of follow-up (130.1 \pm 42.2 months vs $132.7 \pm 49.7$ months, $p=0.673$ ), extraintestinal symptoms (26.0\% vs $16.3 \%, p=0.083)$, or family history of IBD (9.8\% vs 4.1\%, p=0.106). At the time of diagnosis, 26 PCD patients (21.1\%) had disease located in L1, 25 (20.3\%) in L2, 70 (56.9\%) in L3, and two (1.6\%) in L4, whereas 32 NPCD patients (32.7\%) had disease located in L1, 26 (26.5\%) in L2, 40

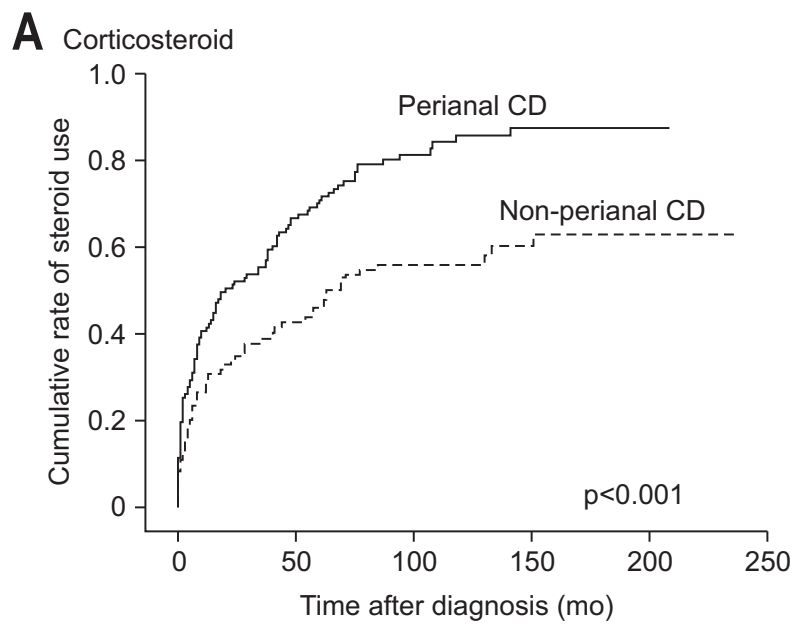

\begin{tabular}{ccc}
\hline Time $(\mathrm{yr})$ & Perianal CD & Non-perianal CD \\
\hline 1 & 41.5 & 29.6 \\
3 & 55.3 & 38.8 \\
5 & 70.7 & 45.9 \\
10 & 82.1 & 55.1 \\
15 & 82.9 & 58.2 \\
\hline
\end{tabular}

C Anti TNF- $\alpha$

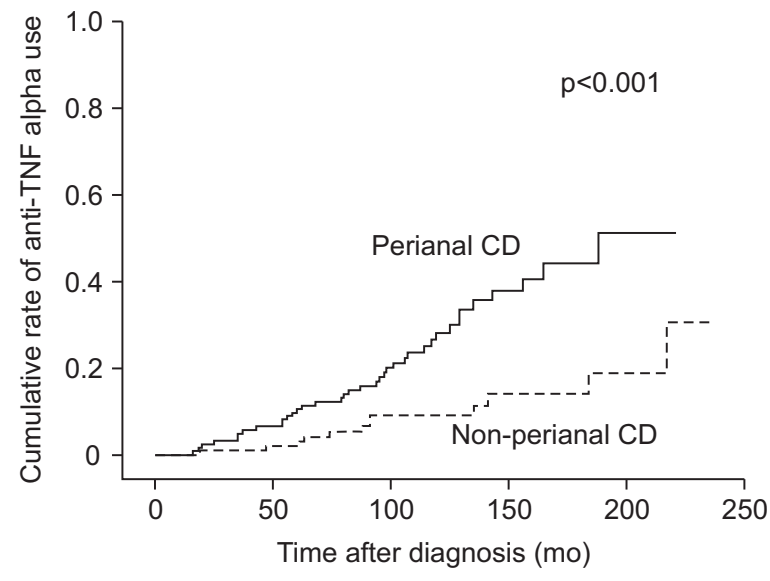

\begin{tabular}{ccc}
\hline Time $(y r)$ & Perianal CD & Non-perianal CD \\
\hline 1 & 0 & 0 \\
3 & 4.9 & 1.0 \\
5 & 10.6 & 2.0 \\
10 & 23.6 & 8.2 \\
15 & 29.3 & 10.2 \\
\hline
\end{tabular}

(40.8\%) in L3, and none in L4. Disease behavior in PCD at diagnosis was inflammatory (B1) type in 70 patients (56.9\%), structuring (B2) in 31 patients (25.2\%), and penetrating (B3) in 22 patients (17.9\%). Fifty-eight (59.2\%) of the NPCD patients were diagnosed with B1 type behavior, 21 (21.4\%) with B2, and 19 (19.4\%) with B3. Fig. 2 shows the trends of change in behavior distribution during the course of PCD and NPCD. Twenty years after diagnosis, PCD exhibited type B1 behavior in 26.8\% of cases, B2 in 15.4\%, and B3 in 57.5\%, whereas the NPCD behaviors were show in 39.8\%, 16.3\%, and 43.9\%, respectively.

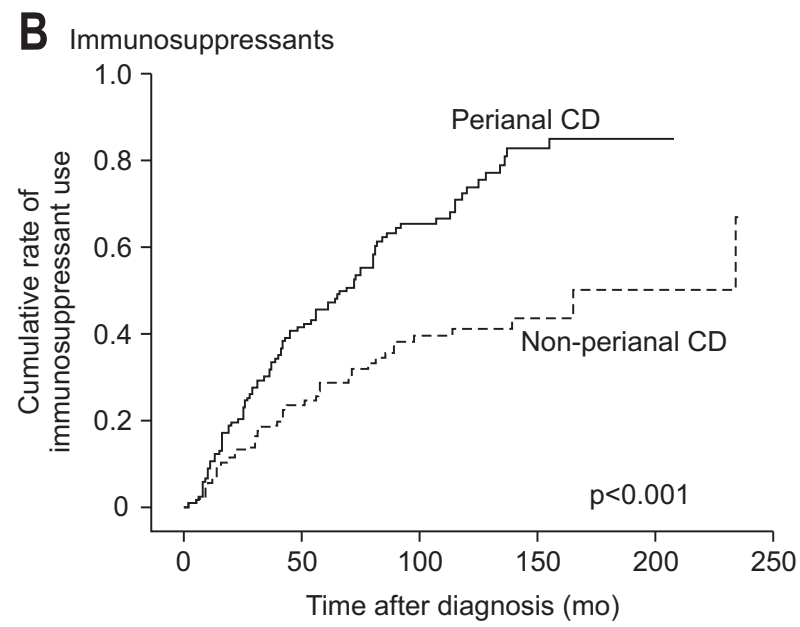

\begin{tabular}{ccc}
\hline Time $(\mathrm{yr})$ & Perianal CD & Non-perianal CD \\
\hline 1 & 10.6 & 7.1 \\
3 & 31.8 & 18.4 \\
5 & 45.5 & 28.6 \\
10 & 67.5 & 38.8 \\
15 & 72.4 & 41.8 \\
\hline
\end{tabular}

Fig. 3. Cumulative probability of medication use. (A) Corticosteroid, (B) immunosuppressants, (C) anti-TNF- $\alpha$. TNF- $\alpha$, tumor necrosis factor $\alpha$; CD, Crohn's disease. 


\section{Comparisons of treatment course}

Table 2 shows the comparison of overall medication prescriptions for PCD and NPCD. Systemic corticosteroids were prescribed for 102 PCD patients (82.9\%) and 57 NPCD patients $(58.2 \%)$ at diagnosis or during the follow-up period. The cumulative probabilities of steroid administration were $41.5 \%$ after 1 year, 55.3\% after 3 years, 70.7\% after 5 years, 82.1\% after 10 years, and $82.9 \%$ after 15 years among PCD patients and 29.6\%, 38.8\%, 45.9\%, 55.1\%, and 58.2\%, respectively, among NPCD patients (Fig. 3). Details of the clinical outcomes regarding corticosteroid use are given in Table 2. The mean frequency of disease flare-up events requiring steroid administration was $3.3 \pm 2.3$ in PCD patients and $2.4 \pm 1.9$ in NPCD ( $\mathrm{p}=0.015)$. The mean total duration of steroid administration was $372.2 \pm 577.2$ days in PCD and 226.7 \pm 205.8 days in NPCD ( $p=0.068)$, and the mean days of steroid administration per event of disease flareup was $108.4 \pm 114.5$ and $94.6 \pm 45.5$ days, respectively $(\mathrm{p}=0.383)$.
Immunosuppressants (azathioprine or 6-mercaptopurine) were administered to 89 patients (72.4\%) with PCD and 57 (58.2\%) with NPCD. The cumulative probabilities of immunosuppressant use were $10.6 \%$ after 1 year, 31.8\% after 3 years, $45.5 \%$ after 5 years, 67.5\% after 10 years, and 72.4\% after 15 years among PCD patients and 7.1\%, 18.4\%, 28.6\%, 38.8\%, and 41.8\%, respectively, among NPCD patients (Fig. 3). Details of clinical outcomes regarding immunosuppressant use are described in Table 2. The mean duration from corticosteroids to first immunosuppressant administration was $26.0 \pm 30.7$ months in PCD and 28.6 \pm 41.8 months in NPCD ( $\mathrm{p}=0.700)$.

Anti-TNF- $\alpha$ agents were used in 37 patients (30.1\%) in PCD and $12(12.2 \%)$ in NPCD $(\mathrm{p}<0.001)$. The cumulative frequency of anti-TNF- $\alpha$ use is shown in Fig. 3. Anti-TNF- $\alpha$ was used in no patients after 1 year, $4.9 \%$ after 3 years, 10.6\% after 5 years, $23.6 \%$ after 10 years, and 29.3\% after 15 years in PCD and in no patients, $1.0 \%, 2.0 \%, 8.2 \%$, and $10.2 \%$, respectively, in NPCD. Details of clinical outcomes regarding anti-TNF- $\alpha$ agents

Table 3. Detailed Clinical Outcomes of the Surgical Treatments and Hospitalizations

\begin{tabular}{|c|c|c|c|}
\hline Variables for clinical outcomes & $\begin{array}{l}\text { Patients with perianal lesions } \\
\qquad(\mathrm{n}=123)\end{array}$ & $\begin{array}{l}\text { Patients without perianal lesions } \\
\qquad(\mathrm{n}=98)\end{array}$ & $\mathrm{p}$-value \\
\hline Surgical treatment & & & 0.097 \\
\hline Yes/no & $49(39.8) / 74(60.2)$ & $50(51.0) / 48(49.0)$ & \\
\hline No. of surgical interventions & & & 0.047 \\
\hline 1 & $27(55.1)$ & $36(72.0)$ & \\
\hline 2 & $12(24.5)$ & $10(20.0)$ & \\
\hline$>2$ & $10(20.4)$ & $4(8.0)$ & \\
\hline Reason for surgery & & & 0.025 \\
\hline Intestinal fistula or abscess & 49 (52.7) & $24(33.3)$ & \\
\hline Obstruction or stricture & $12(12.9)$ & $14(19.4)$ & \\
\hline Perforation & $19(20.4)$ & $13(18.1)$ & \\
\hline Pain due to uncontrolled lesion & $3(3.2)$ & 10 (13.9) & \\
\hline Other & $10(10.8)$ & $11(15.3)$ & \\
\hline Types of operation & & & 0.022 \\
\hline Small bowel resection & $33(35.5)$ & $30(44.8)$ & \\
\hline Right hemicolectomy & $22(23.7)$ & $22(32.8)$ & \\
\hline Ileocecectomy & $9(9.7)$ & $8(11.9)$ & \\
\hline Other colectomy & $27(29.0)$ & $5(7.5)$ & \\
\hline Primary repair & $2(2.2)$ & $2(3.0)$ & \\
\hline Hospitalization & & & 0.086 \\
\hline Yes/no & $101(82.1) / 22(17.9)$ & $71(72.4) / 27(27.6)$ & \\
\hline Among hospitalized patients $(\mathrm{n}=172)$ & 101 & 71 & \\
\hline No. of hospitalizations & $4.6 \pm 4.8$ & $3.2 \pm 2.9$ & 0.016 \\
\hline Total days of hospitalization, day & $54.9 \pm 70.9$ & $42.4 \pm 58.6$ & 0.226 \\
\hline Days per hospitalization, day & $11.8 \pm 11.2$ & $13.9 \pm 11.6$ & 0.222 \\
\hline No. of hospitalizations due to perianal lesions & $0.8 \pm 1.3$ & - & - \\
\hline Total days of hospitalization due to perianal lesions, day & $5.3 \pm 12.2$ & - & - \\
\hline
\end{tabular}

Data are presented as number (\%) or mean \pm SD. 

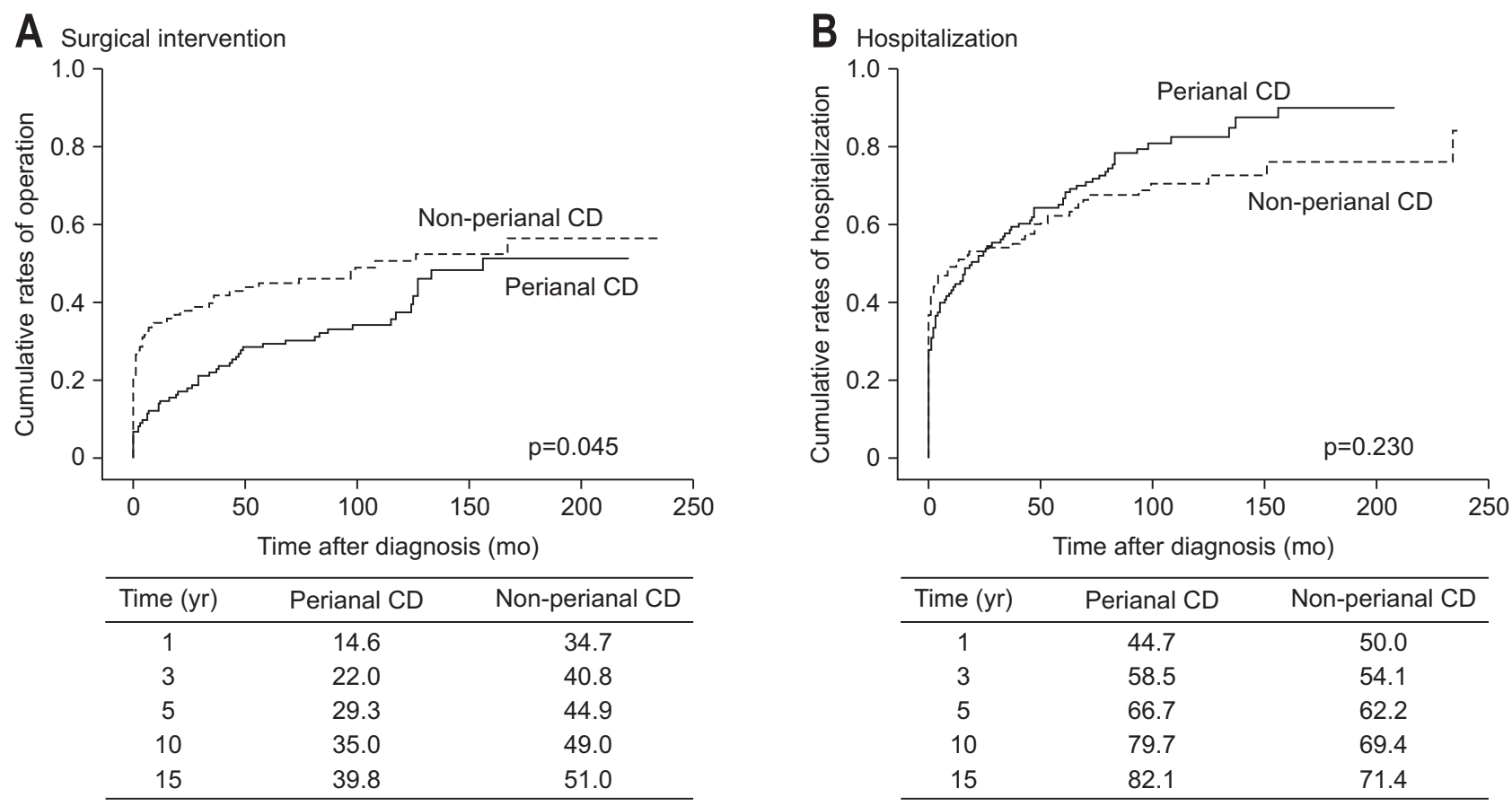

Fig. 4. Cumulative probability of (A) surgical treatment and (B) hospitalization (not counting occasions directly related to perianal lesions). $\mathrm{CD}$, Crohn's disease.

are shown in Table 2. The mean duration from first corticosteroids to first anti-TNF- $\alpha$ administration was $59.2 \pm 40.1$ months in PCD and 64.9 \pm 50.5 months in NPCD ( $\mathrm{p}=0.689)$. The mean duration from first immunosuppressant to first anti-TNF- $\alpha$ administration was $40.6 \pm 36.8$ and $40.2 \pm 39.5$ months in PCD and $\mathrm{NPCD}$, respectively ( $\mathrm{p}=0.971)$.

Forty-nine PCD patients (39.8\%) and 50 NPCD patients $(51.0 \%)$ underwent surgical treatment $(\mathrm{p}=0.097)$. Details are presented in Table 3. PCD patients underwent intestinal resection more than three times more frequently than NPCD patients (20.4\% vs $8.0 \%, p=0.047)$ and had surgery more often for intestinal fistula or abscess, not counting procedures for anal abscesses (56.3\% vs 24.7\%, $\mathrm{p}=0.025$ ). The cumulative rates of surgical intervention are shown in Fig. 4. Although surgical intervention was performed more frequently in NPCD patients than in PCD within 1 year of diagnosis, this modality was applied more frequently to PCD patients than NPCD patients thereafter. Ultimately, there was no significant difference in the proportion of patients receiving surgical intervention between the two groups (39.8\% vs 51.0\%, $\mathrm{p}=0.097$ ).

Hospitalization occurred at least once in 101 patients (82.1\%) with PCD and $71(72.4 \%)$ with NPCD ( $\mathrm{p}=0.086)$. Details associated with hospitalization are summarized in Table 3. The mean frequency of hospitalization was higher in PCD than in NPCD $(4.6 \pm 4.8$ vs $3.2 \pm 2.9, p=0.016)$. There was no significant difference in total days of hospitalization or days per hospitalization between the two groups. Of patients with PCD, the mean frequency and total days of hospitalization related to perianal lesion were $0.8 \pm 1.3$ and $5.3 \pm 12.2$, respectively. The cumulative rates of hospitalization due to $\mathrm{CD}$ itself (leaving out cases directly associated with perianal lesions) are shown in Fig. 4.

\section{DISCUSSION}

In the present study, we first demonstrated the detailed clinical patterns and long-term prognoses of PCD and NPCD in a Korean population across more than 10 years. Our study showed that perianal lesion occurred in 55.7\% of CD patients (123/221), which makes it more prevalent in our study than in earlier Western studies. Previous studies have noted that race might be a factor for occurrence of perianal disease. ${ }^{3,24}$ According to the literature, $14 \%$ to $37 \%$ of Western CD patients and 37\% to $50 \%$ of Asian CD patients experienced perianal disease. ${ }^{15,16,24-29}$ Our results are thus consistent with previous findings that PCD is more common in Asian CD patients than in Western ones. Our data also revealed that perianal lesions were present before or at the diagnosis of $\mathrm{CD}$ in $37.2 \%$ of patients, and that the $\mathrm{cu}-$ mulative rate of PCD 13 years after diagnosis was 55.7\%. Our data showed that, in about two-thirds of patients, PCD was the initial disease presentation, corresponding to an earlier study that found that $46 \%$ of PCD developed before diagnosis. ${ }^{15} \mathrm{We}$ found no significant difference in several factors influencing the development of perianal disease (gender, extraintestinal symptoms, family history of IBD, and previous history of appendectomy), but age was an influential factor. Some of these findings were consistent with previous ones (gender ${ }^{15,24}$ and 
family history of $\mathrm{IBD}^{30}$ ). $\mathrm{CD}$ accompanied by extraintestinal symptoms was more prevalent in PCD than in NPCD (26.0\% vs $16.3 \%)$, but that difference was not significant $(p=0.083)$ in our data, which is dissimilar to the findings of a previous study. ${ }^{18}$ It was previously reported that younger age at diagnosis was associated with PCD. ${ }^{3,10,24}$ Eglinton et al..$^{10}$ found that the mean age at diagnosis was 8.1 years younger for PCD (30.0 years) than NPCD (38.1 years), while we found a difference of 6.9 years (23.4 years vs 30.3 years).

Previous studies of the relationship between CD behavior and perianal disease yielded varying results. Some studies reported that perianal disease represents a factor for complicated behavior such as penetrating and structuring disease. ${ }^{10,24}$ Others found that PCD and complicated types had no association. ${ }^{31,32}$ Our longitudinal observation demonstrated that the disease behavior at diagnosis did not differ significantly between PCD and NPCD. However, patients with PCD progressed more rapidly from inflammatory to complicated behavior over the course of the disease than those with NPCD. After 20 years, there was a pronounced difference in terms of disease behavior between the two groups. The proportions of B1, B2, and B3 in PCD changed from 57\%, 25\%, and 18\%, respectively, at diagnosis to $27 \%$, 15\%, and 58\% after 20 years, whereas those same proportions in NPCD changed from 59\%, 21\%, and 19\% at diagnosis to $40 \%, 16 \%$, and 44\% 20 years later. In terms of disease location, we also found that colonic involvement was more common in PCD (79\%) than in NPCD (67\%), consistent with earlier published data, reinforcing the theory that PCD occurs less often in ileal CD and more often in CD that involves the colon. ${ }^{15,33}$ In contrast to disease behavior, which changed dramatically, disease location was relatively stable and not significantly different between the disease types in the present study: only 13 PCD cases and 12 NPCD cases progressed to the ileocolonic category, similar to reports in previous studies. ${ }^{4,7,28}$

It has been shown that patients with PCD experience a more severe luminal disease course and often require multiple surgical interventions and intensive medical therapies. ${ }^{7,9,10,17,19,34}$ We observed that patients with PCD had a significantly higher cumulative rate of administration of all medicines: corticosteroids, immunosuppressants such as azathioprine, and anti-TNF- $\alpha$ agents. The overall odds ratio in our study was 3.49 for corticosteroids, 3.49 for immunosuppressants, and 3.08 for anti-TNF- $\alpha$ agents. We found several notable points between PCD and NPCD in medical treatment. In the use of corticosteroids, even though disease flare-up events occurred more frequently in PCD than NPCD (3.3 vs 2.4, $\mathrm{p}=0.015$ ), the difference in the number of days of corticosteroid administration per flare-up event was not significant (108 days vs 95 days, $\mathrm{p}=0.383$ ). Thus, PCD might not be a predictive factor for corticosteroid dependency even though more patients with PCD took this drug. In immunosuppressant use, we found no difference in duration from first corticosteroid to first immunosuppressant use between PCD and NPCD (26.0 months vs 28.6 months, $\mathrm{p}=0.700$ ). In anti-TNF- $\alpha$ use, there was no significant difference in either duration from first corticosteroids to first infliximab administration (59.2 months vs 64.9 months, $\mathrm{p}=0.689$ ) or duration from first immunosuppressants to first infliximab administration (40.6 months vs 40.2 months, $\mathrm{p}=0.971$ ). In other words, the step-up approach, a strategy for treating $\mathrm{CD}$, did not progress more rapidly but only occurred more frequently in PCD than in NPCD.

Although there was no significant difference in the proportion of patients undergoing surgical treatment (not counting perianal-related operations) between PCD and NPCD in our results (40\% vs 51\%, $p=0.097$ ), the cumulative frequency of surgery was higher in NPCD than in PCD, especially within 1 year. Traditionally, PCD has been considered to carry a risk of bowel resection. ${ }^{15}$ Even though our finding about the early operation rate might be discordant with previous reports, we did find that multiple surgeries were performed more frequently in patients with PCD, similar to the findings of other studies. ${ }^{18,35}$ We assume that the higher early surgical rate in NPCD patients resulted from the following two factors. First, a substantial portion of our patients with critical conditions presented with abdominal pain from intestinal stricture that went unrecognized before $\mathrm{CD}$ diagnosis, probably because $\mathrm{CD}$ is uncommon, so primary clinicians and patients were insufficiently aware of it until an emergency situation arose. Second, patients whose CD involves the terminal ileum are known to have a higher risk for needing surgery. ${ }^{35,36}$ Given that, in our study population, NPCD patients had a much greater proportion of isolated ileal involvement, especially in the terminal ileum, than PCD patients, the higher early rate of bowel resection in NPCD could be also explained by disease location.

The present study has several limitations. First, many patients in our cohort were treated in the era before anti-TNF- $\alpha$ therapy became available. Thus, it was difficult to evaluate how the disease course was ameliorated by the role of anti-TNF- $\alpha$ therapy. Second, the retrospective nature and single-center study design could be vulnerable to selection bias. Third, there was no data dealing with clinical manifestation according to subtype of perianal lesion or perianal fistula (simple vs complex). Despite these limitations, our study has some strengths. We longitudinally monitored more than 10 years of quantifiable measures on disease course and detailed variables for multidisciplinary treatment modalities in comparing PCD and NPCD.

In conclusion, we demonstrated that patients with PCD were associated with younger age at diagnosis and more considerable changes in disease behavior to the structuring or penetrating types than patients with NPCD. In term of medical treatment, PCD patients were more likely to need corticosteroids, immunosuppressants, and anti-TNF- $\alpha$ agents than NPCD patients. Whereas there were relatively similar rates in surgical interventions and hospitalizations between PCD and NPCD. These findings could help clinicians and researchers understand PCD as a 
distinct disease phenotype and pursue better targeted treatments for PCD patients.

\section{CONFLICTS OF INTEREST}

No potential conflict of interest relevant to this article was reported.

\section{REFERENCES}

1. Steinhart AH, Girgrah N, McLeod RS. Reliability of a Crohn's disease clinical classification scheme based on disease behavior. Inflamm Bowel Dis 1998;4:228-234.

2. Gasche C, Scholmerich J, Brynskov J, et al. A simple classification of Crohn's disease: report of the Working Party for the World Congresses of Gastroenterology, Vienna 1998. Inflamm Bowel Dis 2000;6:8-15.

3. Cosnes J, Cattan S, Blain A, et al. Long-term evolution of disease behavior of Crohn's disease. Inflamm Bowel Dis 2002;8:244-250.

4. Louis E, Collard A, Oger AF, Degroote E, Aboul Nasr El Yafi FA, Belaiche J. Behaviour of Crohn's disease according to the Vienna classification: changing pattern over the course of the disease. Gut 2001;49:777-782.

5. Sachar DB, Bodian CA, Goldstein ES, et al. Is perianal Crohn's disease associated with intestinal fistulization? Am J Gastroenterol 2005;100:1547-1549.

6. Silverberg MS, Satsangi J, Ahmad T, et al. Toward an integrated clinical, molecular and serological classification of inflammatory bowel disease: report of a Working Party of the 2005 Montreal World Congress of Gastroenterology. Can J Gastroenterol 2005;19 Suppl A:5A-36A.

7. Tarrant KM, Barclay ML, Frampton CM, Gearry RB. Perianal disease predicts changes in Crohn's disease phenotype-results of a population-based study of inflammatory bowel disease phenotype. Am J Gastroenterol 2008;103:3082-3093.

8. Eglinton T, Reilly M, Chang C, Barclay M, Frizelle F, Gearry R. Ileal disease is associated with surgery for perianal disease in a population-based Crohn's disease cohort. Br J Surg 2010;97:11031109.

9. Beaugerie L, Seksik P, Nion-Larmurier I, Gendre JP, Cosnes J. Predictors of Crohn's disease. Gastroenterology 2006;130:650-656.

10. Eglinton TW, Roberts R, Pearson J, et al. Clinical and genetic risk factors for perianal Crohn's disease in a population-based cohort. Am J Gastroenterol 2012;107:589-596.

11. Nasir BF, Griffiths L, Nasir A, et al. Perianal disease combined with NOD2 genotype predicts need for IBD-related surgery in Crohn's disease patients from a population-based cohort. J Clin Gastroenterol 2013;47:242-245.

12. Kaur M, Panikkath D, Yan X, et al. Perianal Crohn's disease is associated with distal colonic disease, stricturing disease behavior, IBD-associated serologies and genetic variation in the JAK-STAT pathway. Inflamm Bowel Dis 2016;22:862-869.
13. Eglinton TW, Barclay ML, Gearry RB, Frizelle FA. The spectrum of perianal Crohn's disease in a population-based cohort. Dis Colon Rectum 2012;55:773-777.

14. Ingle SB, Loftus EV Jr. The natural history of perianal Crohn's disease. Dig Liver Dis 2007;39:963-969.

15. Schwartz DA, Loftus EV Jr, Tremaine WJ, et al. The natural history of fistulizing Crohn's disease in Olmsted County, Minnesota. Gastroenterology 2002;122:875-880.

16. Ye BD, Yang SK, Cho YK, et al. Clinical features and long-term prognosis of Crohn's disease in Korea. Scand J Gastroenterol 2010;45:1178-1185.

17. Moon CM, Park DI, Kim ER, et al. Clinical features and predictors of clinical outcomes in Korean patients with Crohn's disease: a Korean association for the study of intestinal diseases multicenter study. J Gastroenterol Hepatol 2014;29:74-82.

18. Han YM, Kim JW, Koh SJ, et al. Patients with perianal Crohn's disease have poor disease outcomes after primary bowel resection. J Gastroenterol Hepatol 2016;31:1436-1442.

19. Thia KT, Sandborn WJ, Harmsen WS, Zinsmeister AR, Loftus EV Jr. Risk factors associated with progression to intestinal complications of Crohn's disease in a population-based cohort. Gastroenterology 2010;139:1147-1155.

20. Loftus EV Jr, Silverstein MD, Sandborn WJ, Tremaine WJ, Harmsen WS, Zinsmeister AR. Crohn's disease in Olmsted County, Minnesota, 1940-1993: incidence, prevalence, and survival. Gastroenterology 1998;114:1161-1168.

21. American Gastroenterological Association Clinical Practice Committee. American Gastroenterological Association medical position statement: perianal Crohn's disease. Gastroenterology 2003;125:1503-1507.

22. Satsangi J, Silverberg MS, Vermeire S, Colombel JF. The Montreal classification of inflammatory bowel disease: controversies, consensus, and implications. Gut 2006;55:749-753.

23. Hanauer SB. Crohn's disease: step up or top down therapy. Best Pract Res Clin Gastroenterol 2003;17:131-137.

24. Tang LY, Rawsthorne P, Bernstein CN. Are perineal and luminal fistulas associated in Crohn's disease? A population-based study. Clin Gastroenterol Hepatol 2006;4:1130-1134.

25. Lapidus A, Bernell 0, Hellers G, Löfberg R. Clinical course of colorectal Crohn's disease: a 35-year follow-up study of 507 patients. Gastroenterology 1998;114:1151-1160.

26. Kim HD, Kim CG, Kim JW, et al. Clinical features and therapeutic responses of perianal lesions in Crohn's disease. Korean J Gastroenterol 2003;42:128-133.

27. Kim JY, Yang SK, Byeon JS, et al. The incidence and natural history of perianal fistulas in Korean patients with Crohn's disease. Intest Res 2006;4:22-31.

28. Chow DK, Leong RW, Lai LH, et al. Changes in Crohn's disease phenotype over time in the Chinese population: validation of the Montreal classification system. Inflamm Bowel Dis 2008;14:536541.

29. Leong RW, Lau JY, Sung JJ. The epidemiology and phenotype 
of Crohn's disease in the Chinese population. Inflamm Bowel Dis 2004;10:646-651.

30. Dorn SD, Abad JF, Panagopoulos G, Korelitz BI. Clinical characteristics of familial versus sporadic Crohn's disease using the Vienna Classification. Inflamm Bowel Dis 2004;10:201-206.

31. Veloso FT, Ferreira JT, Barros L, Almeida S. Clinical outcome of Crohn's disease: analysis according to the vienna classification and clinical activity. Inflamm Bowel Dis 2001;7:306-313.

32. Smith BR, Arnott ID, Drummond HE, Nimmo ER, Satsangi J. Disease location, anti-Saccharomyces cerevisiae antibody, and NOD2/ CARD15 genotype influence the progression of disease behavior in Crohn's disease. Inflamm Bowel Dis 2004;10:521-528.
33. Kanaan Z, Ahmad S, Bilchuk N, Vahrenhold C, Pan J, Galandiuk S. Perianal Crohn's disease: predictive factors and genotypephenotype correlations. Dig Surg 2012;29:107-114.

34. Eglinton TW, Gearry RB. Clinical factors predicting disease course in Crohn's disease. Expert Rev Clin Immunol 2010;6:41-45.

35. Bernell 0, Lapidus A, Hellers G. Risk factors for surgery and postoperative recurrence in Crohn's disease. Ann Surg 2000;231:3845.

36. Oriuchi T, Hiwatashi N, Kinouchi Y, et al. Clinical course and longterm prognosis of Japanese patients with Crohn's disease: predictive factors, rates of operation, and mortality. J Gastroenterol 2003;38:942-953. 